University of Nebraska - Lincoln

DigitalCommons@University of Nebraska - Lincoln

Faculty Papers and Publications in Animal

Science

Animal Science Department

January 1981

\title{
COMPARISONS OF MATING SYSTEMS WITH DUROC, HAMPSHIRE AND YORKSHIRE BREEDS OF SWINE FOR EFFICIENCY OF SWINE PRODUCTION
}

\author{
E. R. Wilson \\ Oklahoma State University, Stillwater \\ R. K. Johnson \\ University of Nebraska-Lincoln, rjohnson5@unl.edu
}

Follow this and additional works at: https://digitalcommons.unl.edu/animalscifacpub

Part of the Animal Sciences Commons

Wilson, E. R. and Johnson, R. K., "COMPARISONS OF MATING SYSTEMS WITH DUROC, HAMPSHIRE AND YORKSHIRE BREEDS OF SWINE FOR EFFICIENCY OF SWINE PRODUCTION" (1981). Faculty Papers and Publications in Animal Science. 20.

https://digitalcommons.unl.edu/animalscifacpub/20

This Article is brought to you for free and open access by the Animal Science Department at DigitalCommons@University of Nebraska - Lincoln. It has been accepted for inclusion in Faculty Papers and Publications in Animal Science by an authorized administrator of DigitalCommons@University of Nebraska - Lincoln. 


\title{
COMPARISONS OF MATING SYSTEMS WITH DUROC, HAMPSHIRE AND YORKSHIRE BREEDS OF SWINE FOR EFFICIENCY OF SWINE PRODUCTION ${ }^{1}$
}

\author{
E. R. Wilson ${ }^{2}$ and R. K. Johnson ${ }^{3}$ \\ Oklaboma State University, Stillwater 74074
}

\begin{abstract}
Summary
Estimates of direct and maternal genetic and heterosis effects for purebreds and crosses among the Duroc, Hampshire and Yorkshire breeds were made from data on 1,243 litters from the Oklahoma crossbreeding experiment. The estimates were used to simulate the production efficiency of 21 mating systems. Each mating system was defined to include purebred, crossbred and commercial matings needed to maintain 10,000 farrowings. Linear programming was used to maximize the number of Yorkshire equivalent pigs for each system. An index of economic weights for days to $100 \mathrm{~kg}$, feed efficiency and probe backfat (traits expressed as a deviation from Yorkshire) was calculated for each breed cross. The index was multiplied by the number of pigs weaned to give the number of Yorkshire equivalent pigs for each cross. The mating system in which market animals were produced by the back-crossing of Yorkshire males to $F_{1}$ Duroc-Yorkshire $(Y \times$ DY) females produced the greatest number of Yorkshire equivalent pigs per 10,000 farrowings. The specific breed combination of Duroc males $x$ Hampshire-Yorkshire females ( $\times$ HY) ranked the highest in production efficiency but when all matings needed to support the system were included, the number of Yorkshire equivalent pigs produced was $96.9 \%$ of the $\mathrm{Y} \times \mathrm{DY}$ system. The relative efficiency of various crossbreeding systems for number of index value pigs was: purebreds, 100 ; two-breed terminal crosses, 115; backcrosses, 122; two-
\end{abstract}

\footnotetext{
'Journal Article 3643 of the Agr. Exp. Sta, Oklahoma State Univ., Stillwater. Research conducted by the Dept of Anim. Sci. (Project 1620) in cooperation with the USDA, ARS, Southern Region.

${ }^{2}$ Kleen Leen Inc., 2720 First Ave, NE, Cedar Rapids, IA 52403.

${ }^{3}$ Dept of Anim. Sci., Univ. of Nebraska, Lincoln 68583.
}

breed rotations, 123 ; rotation female $\times$ terminal male, 124; three-breed rotation, 125 ; threebreed terminals, 127.

(Key Words: Swine Crossbreeding, Mating Systems.)

\section{Introduction}

The advantages of crossbreeding for commercial swine production are well documented. However, recommendations on mating systems have been based on comparisons of specific crosses, with little consideration of the cost of maintaining the purebred and(or) multiplier herds needed to support the system.

Moav (1966a,b) developed methods for comparing specific crossbred progeny for economical profitability by economic weighting of reproductive and performance traits of various breeds and breed combinations; however, this does not consider the cost of the parental purebred herds. Dickerson (1973) compared hypothetical swine populations in several mating systems considering the cost of maintaining the purebred and multiplier levels. Static two-breed crosses were $15 \%$ less efficient than static three-breed crosses. Mating systems for other livestock species have been examined by several authors (Dickerson, 1973; Cartwright et al., 1975; Nitter 1978).

The objectives of this study were to estimate direct genetic effects, maternal effects and individual and maternal heterosis for the Duroc, Hampshire and Yorkshire breeds and to use the estimates to evaluate the efficiency of several mating systems. In addition, the effects on pig production of varied sow replacement rates and of two gilt selection intensities were investigated for several selected mating systems.

\section{Materials and Methods}

The data were taken from three earlier 26 experiments in which pure-bred, two-breed, 
three-breed cross and backcross pigs of Duroc, Hampshire and Yorkshire breeding were produced (Young et al., 1976a, b; Johnson et $a l$, 1978; Wilson and Johnson, 1980).

The experiments were composed of three phases. The first phase compared purebred with two-breed cross matings, the second compared two-breed and three-breed crosses and the third compared backcrosses with three-breed crosses. A total of 1,243 litters was included in the analyses.

Breed cross means were used to estimate certain genetic parameters defined by Dickerson (1969). Genetic effects estimated were: $g_{A}^{I}, g_{A}^{m}$, $h_{A B}^{\mathrm{I}}$ and $h_{A B}^{m}$ for Duroc, Hampshire and Yorkshire, were $g_{A}^{I}$ is the deviation due to average effects of the individual's own genes of breed $A, g_{A}^{m}$ is the deviation due to the average effect through maternal environment for genes of breed $A$ dams, $h_{A B}^{I}$ is the deviation due to increased average heterozygosity of $F_{1}$ crossbreds from the crossing of breeds $A$ and $B$ and $h_{A B}^{m}$ is similar to $h_{A}^{I}$, except that it is the effect of using a crossbred dam from a cross between breeds A and B. Dickerson (1969) included additional genetic effects such as deviations due to grandmaternal effects, grandmaternal heterosis and recombination, but these could not ve estimated from the data used here and were ignored. The model assumes a linear relationship between degree of heterozygosity and amount of heterosis (Dickerson, 1969).

The data were analyzed with the following linear model:

$$
\mathrm{Y}=\mathbf{X b}+\mathbf{e},
$$

where (1) $Y$ is a $20 \times 1$ vector of breed cross means, (2) $X$ is a $30 \times 13$ design matrix based on genetic expectations of means, (3) $b$ is a 13 $x 1$ vector of parameters which includes: $u-a$ common constant; $P_{i}$ - random effect of phase, $i=1,2,3 ; g_{J}^{I}$ - direct genetic effect, $j=1,2,3$, $\mathrm{g}_{\mathrm{k}}^{\mathrm{m}}$ - maternal genetic effect, $\mathrm{k}=1,2,3, \mathrm{~h}_{\mathrm{l}}^{\mathrm{I}}$ individual heterosis, $1=1,2,3 ; h_{n}^{m}$ - maternal heterosis, $n=1,2,3$; and (4) e is a $30 \times 1$ vector having a multivariate distribution with mean zero and variance-covariance matrix $V$, where $V$ is a $30 \times 30$ diagonal matrix with the reciprocal of the number of observations in each breed-cross mean on the diagonal.

Generalized least squares were used for obtaining solutions to the equations with the following restrictions: $\sum_{i=1}^{3} P_{i}=\sum_{j=1}^{3} g_{j}^{I}=\sum_{k=1}^{3} g_{k}^{m}$
$=0$. Traits of interest in these analyses were number of pigs at 42 days of age, days and average backfat probe at $100 \mathrm{~kg}$ and feed efficiency. Predicted values were calculated for purebreds, two-breed crosses, three-breed crosses, backcrosses and various rotation crosses.

Mating Systems. Mating systems were defined to include the entire population of purebred and crossbred herds needed to maintain and provide breeding stock as replacements for a particular mating structure. The efficiencies of different mating systems could be compared on a total economic basis (Cartwright et al., 1975) or by the amount of product produced per female in the herd (Dickerson, 1973; Nitter, 1978). Harris (1970) formulated the following equations for evaluating the expense and income per individual pig:

$$
\begin{gathered}
P=\text { production cost of a pig }=\left(\begin{array}{l}
\text { slaughter } \\
\text { cost }
\end{array}\right)+ \\
\left(\begin{array}{l}
\text { cost per } \\
\text { unit feed }
\end{array}\right)\left(\begin{array}{l}
\text { feed } \\
\text { consumption }
\end{array}\right)+ \\
\left(\begin{array}{l}
\text { labor and } \\
\text { facilities cost } \\
\text { per unit time }
\end{array}\right)\left(\begin{array}{l}
\text { time to } \\
\text { reach } \\
\text { slaughter }
\end{array}\right) ; \\
R=\text { reproduction cost }=\left(\begin{array}{l}
\text { no. of } \\
\text { litters }
\end{array}\right) \\
\left(\begin{array}{l}
\text { sow and litter }+\begin{array}{l}
\text { sow and litter } \\
\text { feed costs }
\end{array}+ \\
\text { boar costs costs } \\
\text { per litter }
\end{array}\right) ;
\end{gathered}
$$

$$
\begin{gathered}
\text { Rep }=\text { replacement cost }=\left(\begin{array}{l}
\text { cost of gilt } \\
\text { production }
\end{array}\right)- \\
\left(\begin{array}{l}
\text { salvage } \\
\text { value from } \\
\text { old sows }
\end{array}\right), \text { and } \\
\mathrm{N}=\text { number of pigs }=\left(\begin{array}{l}
\text { no. of } \\
\text { litters }
\end{array}\right)\left(\begin{array}{l}
\text { avg litter } \\
\text { size }
\end{array}\right) \\
\left(\begin{array}{l}
\text { pig } \\
\text { survival }
\end{array}\right) .
\end{gathered}
$$

Then expense $=E=P+\frac{R+\text { Rep }}{N} ;$ Income $=I=$ (carcass weight) (value per unit of weight), and 
Total profit $=N(I-E)=N(I)-N(P)-R-$ Rep.

This can be extended to compare two mating systems, $S_{1}$ and $S_{2}$, in which the total number of litters farrowed is fixed. Then $R_{1}$ equals $R_{2}$ if litter costs are independent of litter size. This assumption probably is not true, but differences should be quite small. Thus, the difference (D) between two mating systems is (total profit) $)_{1}$ (total profit $)_{2}=\mathrm{N}_{1}\left(\mathrm{I}_{1}\right)$ $N_{1}\left(P_{1}\right)-R_{1}-\operatorname{Rep}_{1}-\left(N_{2}\left[I_{2}-P_{2}\right]-R_{2}-\right.$ Rep $\left.)_{2}\right)$, which reduces to $N_{1}\left(I_{1}-P_{1}\right)-N_{2}\left(I_{2}\right.$ $\left.-\mathbf{P}_{2}\right)+\operatorname{Rep}_{2}-\operatorname{Rep}_{1}$.

If the salvage value of a sow is equivalent to the cost of raising a gilt from birth until the time she enters the breeding herd and is bred, then Rep will be zero and the difference between $\operatorname{Rep}_{1}$ and $\operatorname{Rep}_{2}$ will be zero. Then $\mathrm{D}=$ $N_{1}\left(I_{1}-P_{1}\right)-N_{2}\left(I_{2}-P_{2}\right)$. If the assumption is not true, differences between two mating systems with different conception rates will be biased, because systems with lower conception rates need to retain more gilts. Mating systems were first compared assuming that gilt replacement costs equals sow salvage value. A second comparison was made assuming that replacement gilt costs are equal to the salvage value of a sow plus one-half the value of a Yorkshire equivalent pig.
For each mating system there are several breed combinations that make up the total pig production. Each breed combination has its own value for the quantity $(I-P)$, which is equal to:

carcass value $-\left(\begin{array}{l}\text { cost per } \\ \text { unit feed }\end{array}\right)\left(\begin{array}{l}\text { feed } \\ \text { consumption }\end{array}\right)-$

$$
\left(\begin{array}{l}
\text { labor and } \\
\text { facilities cost } \\
\text { per unit time }
\end{array}\right)\left(\begin{array}{l}
\text { time to } \\
\text { reach } \\
\text { slaughter }
\end{array}\right)
$$

Therefore, $N(I-P)$ is $\sum_{i=1}^{k} n_{i}\left(I_{i}-P_{i}\right)$, where $n_{i}$, $I_{i}$ and $P_{i}$ are the number of pigs, carcass value and production costs of the $\mathrm{i}^{\text {th }}$ breed group. Cost of labor, feed per unit and fixed costs per day should be constant for each system. The major production costs between weaning and $100 \mathrm{~kg}$ are feed and fixed costs per day. Differences in carcass value at a fixed weight are primarily due to differences in carcass composition. Thus, the quantity of interest is an economic weighting of the variables responsible for a major portion of the variation between breed groups in net income. The quantity $\left(I_{i}-\right.$ $P_{i}$ ) was estimated by the following index:

$$
\text { Index }=\frac{100-.10\left(D_{i}-D_{y}\right)+90\left(F E_{i}-F E_{y}\right)-2.16\left(B F_{i}-B F_{y}\right)}{100}
$$

where

$$
\begin{aligned}
D_{i}= & \text { days to } 100 \mathrm{~kg} \text { for the } \mathrm{i}^{\text {th }} \text { breed } \\
& \text { group, } \\
\mathrm{D}_{\mathrm{y}}= & \text { mean days to } 100 \mathrm{~kg} \text { for Yorkshire, } \\
\mathrm{FE}_{\mathrm{i}}= & \text { gain/feed for the } \mathrm{i}^{\text {th }} \text { breed group; } \\
\mathrm{FE}_{\mathrm{y}}= & \text { gain/feed for Yorkshire, } \\
\mathrm{BF}_{\mathrm{i}}= & \text { backfat probe for the } \mathrm{i}^{\text {th }} \text { breed } \\
& \text { group and } \\
\mathrm{BF}_{\mathrm{y}}= & \text { mean backfat probe for Yorkshire. }
\end{aligned}
$$

The economic values of $-\$ .10$ for each 1 -day decrease in days to $100 \mathrm{~kg}, \$ 90 / \mathrm{unit}$ increase in feed efficiency and $-\$ 2.16 / \mathrm{cm}$ increase in backfat probe are taken from P. J. Cunningham (personal communication). The value of 100 is arbitrary and represents a $100-\mathrm{kg}$ market hog with a value of $\$ 100$; it is the base value for Yorkshire. Changes in market price would change this value but would not affect the index value of systems greatly over normal price ranges. Yorkshire market hogs would have a relative value of 1.00 , with all other breeds and breed crosses expressed in Yorkshire equivalents.

Linear programming techniques were used to find the optimum production from 21 different mating systems involving the Duroc, Hampshire and Yorkshire breeds. Linear programming was readily adaptable since the objective was to maximize the number of pigs produced in a mating system with the constraint that total number of farrowings would be 10,000 . Restrictions on minimum purebred herd size, replacement rates, conception rates and proportion of offspring saved for breeding were imposed for each mating system. The IBM MPSX Linear Programming Package was used.

Model Assumptions and Restrictions. Mating systems were considered to be at equilibrium producing, only as many replacements as needed to maintain the system under the 
restrictions imposed. For each system, the total number of sows farrowing was set at 10,000 . Purebred herds had a minimum of 100 gilts farrowing, and $90 \%$ of the gilts that farrowed were available to be transferred to $F_{1}$ gilt production herds. Conception rates, for the various female breed groups, were: Duroc, 81.6\%; Hampshire, 86\%; Yorkshire, $70.9 \%$; Duroc-Hampshire, $78.1 \%$; Duroc-Yorkshire, 83.4\% and Hampshire-Yorkshire, $82.4 \%$ (Johnson et al., 1978). Conception rate was assumed to be the same for gilts and sows (Young et al., 1976a).

At any level of production, a maximum of $90 \%$ of the gilts that farrowed their first litter could be retained for the breeding herd. For the primary analysis, the average retention rate for purebred sows farrowing crossbred litters was set at $50 \%$ and the retention rate for commercial sows was set at $60 \%$. Average retention rate pertains only to sows that have farrowed two or more litters, and it was calculated as the total number of sows retained divided by the total number of sows available for selection, all of which farrowed two or more litters. Sows were retained at random without regard to parity. Consequently, several parity distributions could have resulted in the same retention rate.

Additional assumptions were that: (1) sows weaned 1.2 more pigs per litter than did gilts of the same breeding (Young et al., 1976a; Johnson et al., 1978); (2) the maximum number of young females saved from purebred or $F_{1}$ litters was $80 \%$ of the gilts weaned; (3) the maximum number of young boars retained for breeding was one-half; (4) boars were utilized at the rate of one per 10 females in the breeding herd and (5) boars were replaced for each pig crop.

Several selected mating systems were compared at various purebred and commercial sow retention rates and at two limits $(.5$ and .8$)$ of the proportion of purebred gilts retained for breeding. These comparisons were made to investigate possible interactions between mating systems and selection intensities.

\section{Results and Discussion}

Breed Effects. The estimates of the genetic parameters for each trait are presented in table 1. The direct genetic effect for Yorkshire was $1.03 \pm .53$ and $1.63 \pm .54$ pigs greater than that for Duroc and Hampshire, respectively, for number of pigs per litter at $\mathbf{4 2}$ days. Similarly, maternal genetic effects for Yorkshire were significantly greater than those for Duroc, $.74 \pm$ .33 pigs, and tended to be larger than those for

TABLE 1. ESTIMATED BREED EFFECTS, INDIVIDUAL HETEROSIS AND MATERNAL HETEROSIS FOR NUMBER OF PIGS AT 42 DAYS, AGE AT $100 \mathrm{KG}$, FEED EFFICIENCY AND BACKFAT PROBE

\begin{tabular}{|c|c|c|c|c|}
\hline Effect & $\begin{array}{l}\text { No. of pigs at } \\
42 \text { days }\end{array}$ & $\begin{array}{l}\text { Days to } \\
100 \mathrm{~kg}\end{array}$ & Gain/feed & $\begin{array}{l}\text { Backfat } \\
\text { probe, cm }\end{array}$ \\
\hline \multicolumn{5}{|l|}{ Direct } \\
\hline $\mathrm{D}-\mathbf{Y}^{\mathbf{a}}$ & $-1.03 \pm .53^{t}$ & $-5.5 \pm 2.6^{*}$ & $.012 \pm .005^{*}$ & $.20 \pm .06^{* *}$ \\
\hline $\mathbf{H}-\mathbf{Y}$ & $-1.63 \pm .54^{* *}$ & $3.5 \pm 2.6$ & $.014 \div .005^{*}$ & $-.45 \pm .06 *$ \\
\hline \multicolumn{5}{|l|}{ Maternal } \\
\hline $\mathrm{D}-\mathrm{Y}$ & $-.74 \pm .33^{*}$ & $.5 \pm 1.6$ & $-.022 \pm .003^{* *}$ & $.22 \pm .04 * *$ \\
\hline $\mathbf{H}-\mathbf{Y}$ & $-.45 \pm .33$ & $-.9 \pm 1.6$ & $-.028 \pm .003^{* *}$ & $.33 \pm .04 * *$ \\
\hline \multicolumn{5}{|c|}{ Ind. heterosis } \\
\hline DH & $1.07 \pm .34^{* *}$ & $-11.0 \pm 1.7^{* *}$ & $.013 \pm .004^{* *}$ & $-.05 \pm .04$ \\
\hline DY & $.88 \pm .34^{*}$ & $-9.6 \pm 1.7^{*} *$ & $.008 \pm .003^{*}$ & $-.07 \pm .04$ \\
\hline HY & $.46 \pm .34$ & $-8.6 \pm 1.7^{* *}$ & $.008 \pm .003^{*}$ & $.04 \pm .04$ \\
\hline \multicolumn{5}{|c|}{ Mat heterosis } \\
\hline DH & $1.39 \pm .34^{* *}$ & $-1.5 \pm 1.6$ & $-.000 \pm .003$ & $-.01 \pm .04$ \\
\hline DY & $1.11 \pm .34^{* *}$ & $-1.4 \pm 1.6$ & $-.001 \pm .003$ & $.06 \pm .04$ \\
\hline HY & $1.16 \pm .34^{* *}$ & $1.6 \pm 1.6$ & $-.000 \pm .003$ & $.05 \pm .04$ \\
\hline
\end{tabular}

${ }^{a_{D}}=$ Duroc, $H=$ Hampshire, $Y=$ Yorkshire.

$t_{P}<10$.

${ }^{*} \mathrm{P}<.05$.

${ }^{*} \mathrm{P}<.01$ 
Hampshire, $.45 \pm .33$ pigs. In contrast, Schneider (1976) found small and nonsignificant differences between these breeds in general combining ability and in maternal effects for number of pigs at 56 days, and Bereskin $e t$ al. (1974) found that maternal effects were nor significant for number of pigs at 56 days in crosses of Yorkshire and Duroc lines that had been selected for low and high backfat.

Estimates of individual heterosis effects for number of pigs at 42 days were $1.07 \pm .34$ pigs for Duroc-Hampshire crosses, $.88 \pm .34$ pigs for Duroc-Yorkshire crosses and $.46 \pm .34$ pigs for Hampshire-Yorkshire crosses. Schneider (1976) reported specific heterosis values of .47 pigs for Duroc-Hampshire, -.58 pigs for DurocYorkshire and -.92 pigs for HampshireYorkshire, all at 56 days. Maternal heterosis for number of pigs at 42 days ranged from 1.11 to $1.39 \mathrm{pigs} / \mathrm{litter}$ and was significant for all crosses.
The direct effect of Duroc for days to 100 $\mathrm{kg}$ was $5.5 \pm 2.6$ days less than that of Yorkshire, and the Yorkshire direct effect was $3.5 \pm$ 2.6 days less than that of Hampshire. Maternal effects for age at $100 \mathrm{~kg}$ were small and not significant. Estimates of individual heterosis for all crosses were highly significant for age at 100 $\mathrm{kg}$, ranging from -11 days for Duroc-Hampshire crosses to $\mathbf{- 8 . 6}$ days for Hampshire-Yorkshire crosses. Maternal heterosis estimates for age at $100 \mathrm{~kg}$ were small and not significant.

For feed efficiency, both Duroc and Hampshire direct effects were significantly greater than Yorkshire direct effects; however, the Yorkshire maternal effect was about twice as great as the direct effect. Yorkshire dams produced offspring that utilized feed more efficiently than pigs from dams of the other two breeds. Similarly Bereskin et al. (1976) found that Yorkshire dams produced pigs that were more efficient than pigs from Duroc dams.

TABLE 2. PREDICTED MEAN PERFORMANCE OF BREED CROSSES FOR NUMBER OF PIGS AT 42 DAYS, AGE AT $100 \mathrm{KG}$, FEED EFFICIENCY AND BACKFAT PROBE

\begin{tabular}{|c|c|c|c|c|c|c|}
\hline $\begin{array}{l}\text { Breeding } \\
\text { type }\end{array}$ & $\begin{array}{l}\text { No. pigs } \\
\text { at } 42 \text { days }\end{array}$ & $\begin{array}{l}\text { Age at } \\
100 \mathrm{~kg}\end{array}$ & $\begin{array}{l}\text { Gain/ } \\
\text { feed }\end{array}$ & $\begin{array}{l}\text { Backfat } \\
\text { probe, cm }\end{array}$ & $\begin{array}{l}\text { Yorkshire } \\
\text { equivalent }\end{array}$ & $\begin{array}{l}\text { No. of Yorkshire } \\
\text { equivalent pigs }\end{array}$ \\
\hline $\begin{array}{l}\mathrm{D} \times \mathrm{D} \\
\mathrm{H} \times \mathbf{H} \\
\mathbf{Y} \times \mathbf{Y}\end{array}$ & $\begin{array}{l}5.48 \\
5.18 \\
7.26\end{array}$ & $\begin{array}{l}187.3 \\
195.0 \\
188.2\end{array}$ & $\begin{array}{l}.310 \\
.307 \\
.321\end{array}$ & $\begin{array}{l}3.33 \\
2.79 \\
2.91\end{array}$ & $\begin{array}{r}.983 \\
.983 \\
1.000\end{array}$ & $\begin{array}{l}5.39 \\
5.09 \\
7.26\end{array}$ \\
\hline $\begin{array}{l}\mathrm{D} \times \mathrm{H} \\
\mathrm{D} \times \mathbf{Y} \\
H \times \mathrm{D} \\
H \times \mathbf{Y} \\
\mathbf{Y} \times \mathrm{D} \\
\mathbf{Y} \times \mathbf{H}\end{array}$ & $\begin{array}{l}6.55 \\
7.62 \\
6.25 \\
6.90 \\
6.88 \\
6.45\end{array}$ & $\begin{array}{l}179.5 \\
178.0 \\
180.8 \\
183.4 \\
178.5 \\
182.5\end{array}$ & $\begin{array}{l}.319 \\
.334 \\
.325 \\
.335 \\
.313 \\
.307\end{array}$ & $\begin{array}{l}3.06 \\
2.94 \\
2.95 \\
2.72 \\
3.16 \\
3.05\end{array}$ & $\begin{array}{r}1.004 \\
1.022 \\
1.010 \\
1.022 \\
.997 \\
.991\end{array}$ & $\begin{array}{l}6.58 \\
7.79 \\
6.31 \\
7.05 \\
6.86 \\
6.39\end{array}$ \\
\hline $\mathrm{D} \times \mathbf{D H}$ & 7.41 & 181.9 & .314 & 3.19 & .995 & 7.37 \\
\hline$D \times D Y$ & 7.67 & 181.3 & .321 & 3.19 & 1.002 & 7.69 \\
\hline $\mathbf{D} \times \mathbf{H Y}$ & 8.24 & 180.3 & .326 & 3.04 & 1.010 & 8.32 \\
\hline $\mathrm{H} \times \mathrm{DH}$ & 7.11 & 186.4 & .316 & 2.87 & .998 & 7.10 \\
\hline $\mathrm{H} \times \mathrm{DY}$ & 7.69 & 180.8 & .329 & 2.90 & 1.015 & 7.81 \\
\hline $\mathbf{H} \times \mathbf{H Y}$ & 7.20 & 190.8 & .321 & 2.80 & 1.000 & 7.20 \\
\hline $\mathbf{Y} \times \mathbf{D H}$ & 8.06 & 179.0 & .310 & 3.10 & .995 & 8.02 \\
\hline $\mathbf{Y} \times \mathbf{D Y}$ & 8.18 & 182.0 & .316 & 3.09 & .998 & 8.16 \\
\hline $\mathbf{Y} \times \mathbf{H Y}$ & 8.01 & 187.0 & .314 & 3.02 & .992 & 7.95 \\
\hline DH rot. & 6.97 & 182.8 & .317 & 3.02 & 1.000 & 6.97 \\
\hline DY rot & 7.70 & 180.5 & .320 & 3.11 & 1.003 & 7.72 \\
\hline HY rot. & 7.30 & 186.9 & .319 & 2.90 & 1.000 & 7.30 \\
\hline $\mathrm{D} \times(\mathrm{HY}$ rot $)$ & 7.86 & 179.8 & .326 & 3.02 & 1.011 & 7.95 \\
\hline $\mathrm{H} \times(\mathrm{DY}$ rot $)$ & 7.32 & 181.2 & .329 & 2.88 & 1.016 & 7.44 \\
\hline $\mathbf{Y} \times(\mathrm{DH}$ rot $)$ & & 179.5 & .310 & 3.10 & .996 & 7.57 \\
\hline DHY rot. & 7.71 & 181.5 & .320 & 3.01 & 1.005 & 7.75 \\
\hline
\end{tabular}

\footnotetext{
${ }^{a} \mathrm{D}=$ Duroc, $\mathrm{H}$ - Hampshire, $\mathrm{Y}=$ Yorkshire. Breed of sire listed first.

${ }^{b}$ Calculated as number of pigs at 42 days $X$ Yorkshire equivalent.
} 
Individual heterosis was significant for feed efficiency, but maternal heterosis was essentially zero.

The direct genetic effect, for average backfat probe, of Hampshire was $.45 \pm .06 \mathrm{~cm}$ less than that of Yorkshire, and the Yorkshire effect was $.20 \pm .06 \mathrm{~cm}$ less than that of Duroc. Nelson and Robison (1976) also reported that Hampshire-sired pigs had less average backfat probe than Yorkshire and Duroc. As with feed efficiency, the Yorkshire maternal effect significantly reduced backfat probe by comparison with Duroc $(-.22 \pm .04 \mathrm{~cm})$ and Hampshire $(-.33 \pm .04 \mathrm{~cm})$. This is in agreement with Bereskin et al. (1971) and Bereskin and Davey (1978). Individual and maternal heterosis estimates were not significantly different from zero for any of the crosses.
The predicted breed or breed cross performance calculated from the estimated genetic effects is shown in table 2 . The rotation crosses were calculated on the basis of the equilibrium heterosis levels and the average direct and maternal effects for the breeds that composed the crosses.

Mating Systems. Figure 1 and table 3 show the numbers of Yorkshire equivalent pigs produced per 10,000 farrowing sows for various mating systems. Each mating system is defined by the breed cross of the market pigs but includes all purebred and crossbred combinations necessary to support the system. Comparisons were made with the restriction that $50 \%$ of the purebred sows farrowing two or more litters and producing crossbred litters would be available for the breeding herd, and

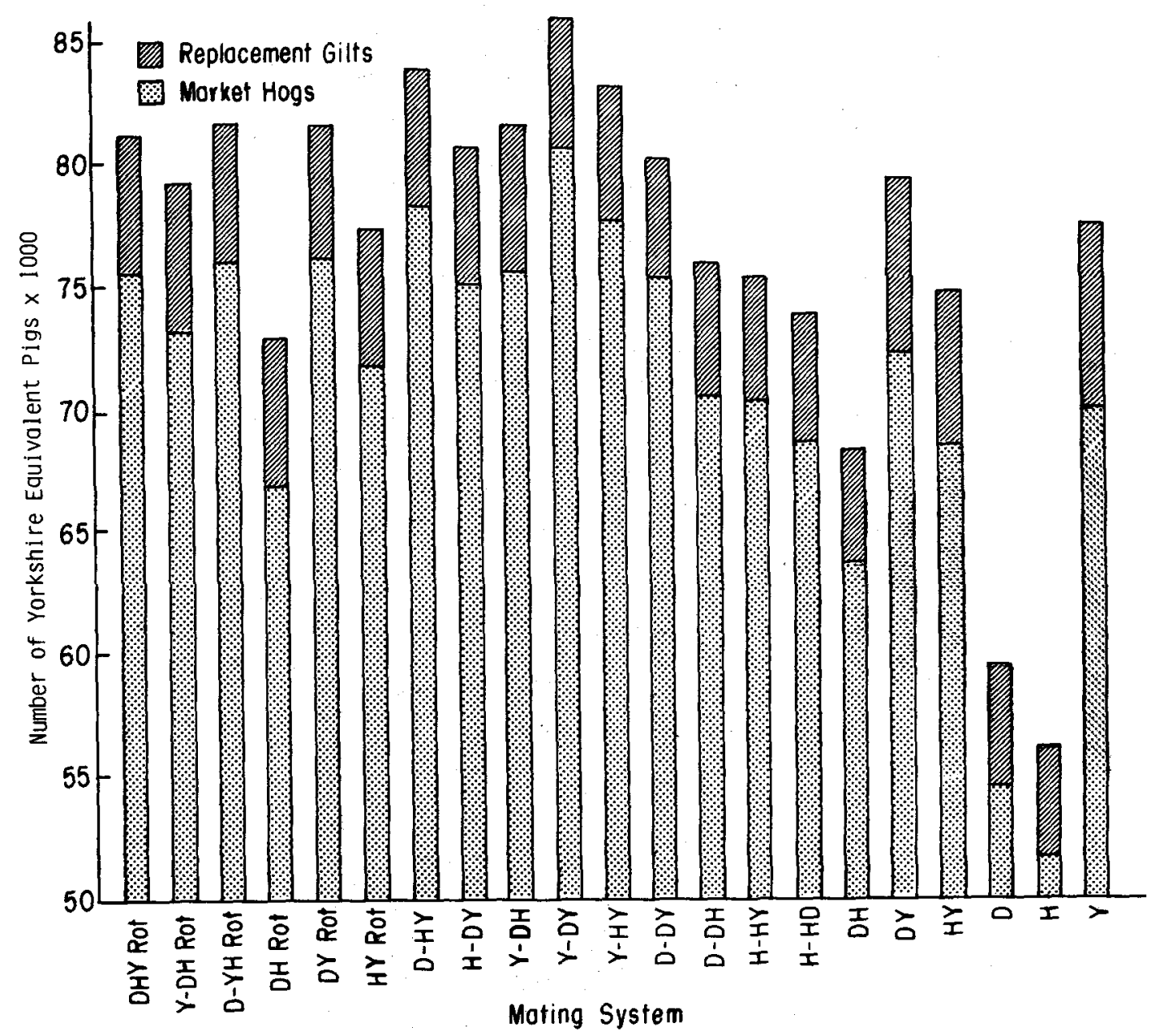

Figure 1. Number of Yorkshire equivalent pigs produced by various mating systems. 


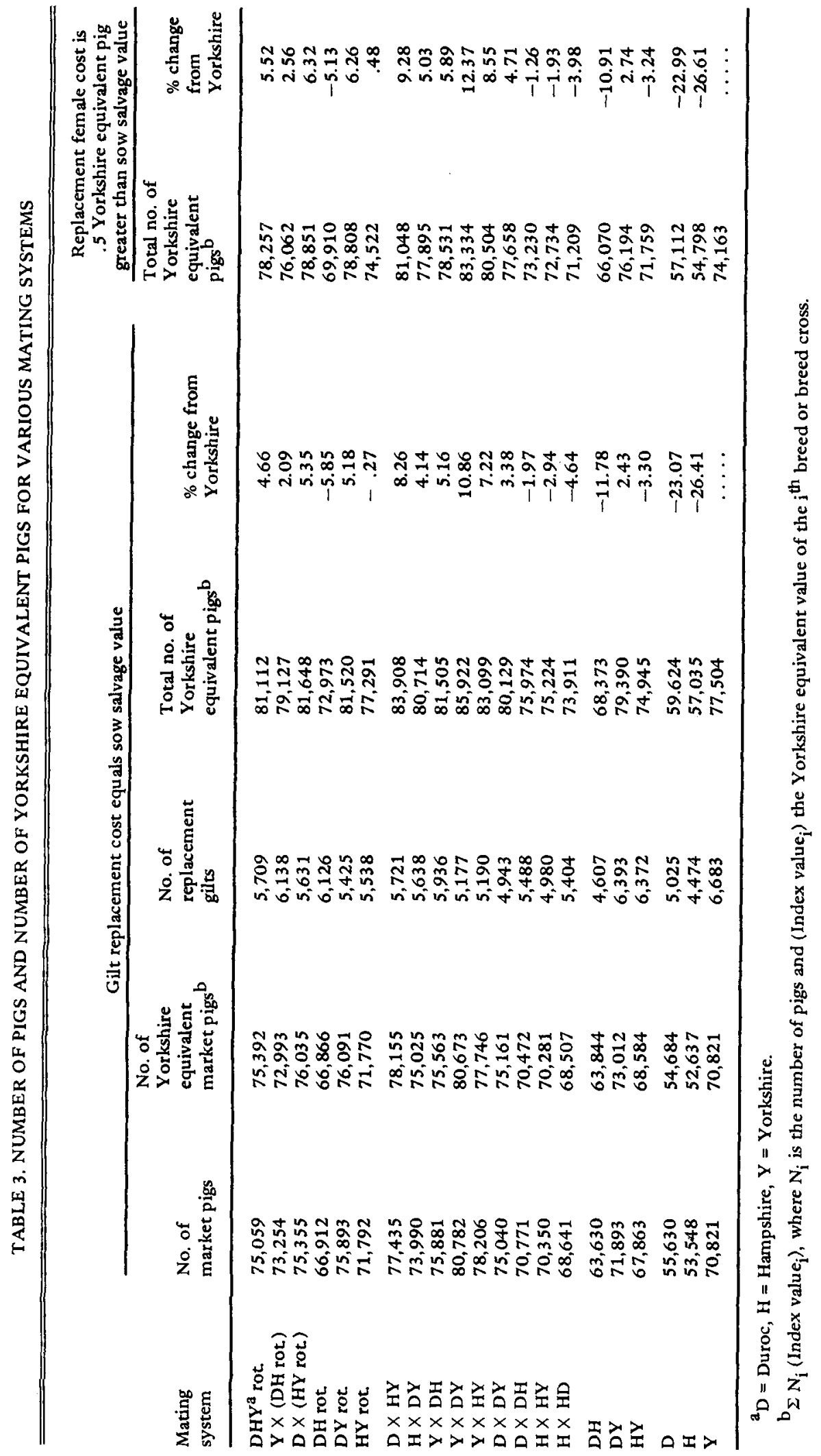


that $60 \%$ of the commercial sows farrowing two or more litters would be available as replacements in the sow herd. The number of gilts available for replacement was limited to $80 \%$ of the female offspring weaned, and gilt replacement costs were assumed to be equal to the salvage value of a sow.

The best three-breed system was the mating of a Duroc sire to a Hampshire-Yorkshire cross female ( $D \times H Y$ ). The mating of Yorkshire sires to Duroc-Hampshire females produced fewer Yorkshire equivalent pigs than the $\mathrm{D} \times \mathrm{HY}$ system. The static three-breed cross of Hampshire $\times$ Duroc-Yorkshire $(H \times D Y)$ produced 2.6\% fewer Yorkshire equivalent pigs than $D X$ HY. Backcrossing a Yorkshire sire to DurocYorkshire females produced $2.4 \%$ more Yorkshire equivalent pigs than the best three-breed static cross, even though the specific breed cross of $\mathrm{D} \times \mathrm{HY}$ had the highest predicted number of Yorkshire equivalent pigs. This was due primarily to the need for only two purebred herds with backcross production and the high litter productivity of the breeds and crosses involved.

Each rotation cross produced fewer pigs than the $D \times H Y$ mating system. Two-breed rotation crosses of Duroc-Yorkshire, Duroc terminal sire on a Hampshire-Yorkshire rotation female and the three-breed rotation cross were all similar. The system of Hampshire boars mated to Duroc-Yorkshire rotation females was considered. However, the Duroc-Yorkshire rotation was more productive and none of the Hampshire-sired pigs was produced; therefore, this system was deleted from further analyses. Although the three-breed rotation maintained a higher proportion of sows farrowing at the commercial level (figure 2), the litter productivity was not at the level of D $\times$ HY crosses.

When the cost of replacement gilts was set equal to the salvage value of a sow plus one-half of a Yorkshire equivalent pig, the rankings of the mating system for total production did not change, except that HY rotation switched position with purebred Yorkshire (table 3). When the higher cost of replacement gilts was considered, the production of all mating systems increased in relation to that of purebred Yorkshires. This was expected since Yorkshires had the lowest conception rate and required the greatest number of replacement gilts.

Figure 2 shows the percentage of sows farrowing at different levels for four selected mating systems. With either three-breed system,

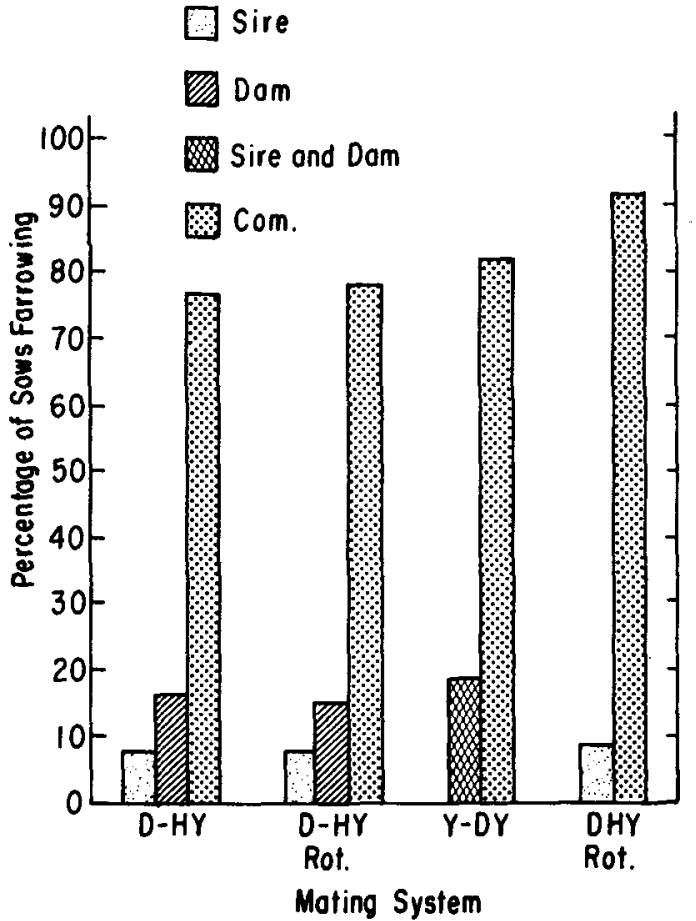

Figure 2. Distribution of farrowing sows for four mating systems.

$\mathrm{D} \times \mathrm{HY}$ or $\mathrm{D} \times$ (HY rotation), the number of sows farrowing in each level was similar. In the $D \times$ HY system, $7.4,16.3$ and $76.3 \%$ of the sows were in sire line, crossbred $F_{1}$ gilt and commercial production, while in the $\mathrm{D} \times$ (HY rotation) system, there were $7.5,15.1$ and $\mathbf{7 7 . 4 \%}$, respectively, in each level of production. The backcross system of $\mathrm{Y} \times \mathrm{DY}$ maintained $18.5 \%$ of its farrowing sows in purebred herds and $81.5 \%$ in commercial production. A threebreed rotation maintained the largest proportion $(91.7 \%)$ of the females in commercial production. The three purebred herds, which supplied sires, composed $8.3 \%$ of the farrowing females for the three-breed rotation.

To estimate the effect of changing selection intensities on present production, we compared six mating systems, setring the proportion of gilts saved at the practical limits of .5 and .8 of purebred gilts produced in the sow lines. Figure 3 gives these comparisons. In the backcross systems ( $\times D Y, Y \times D Y$ and $Y \times H Y$ ), the differences in number of Yorkshire equivalent pigs produced were changed by less than $.1 \%$ when the limit for gilt selection was changed. This was due to an original restriction that one- 


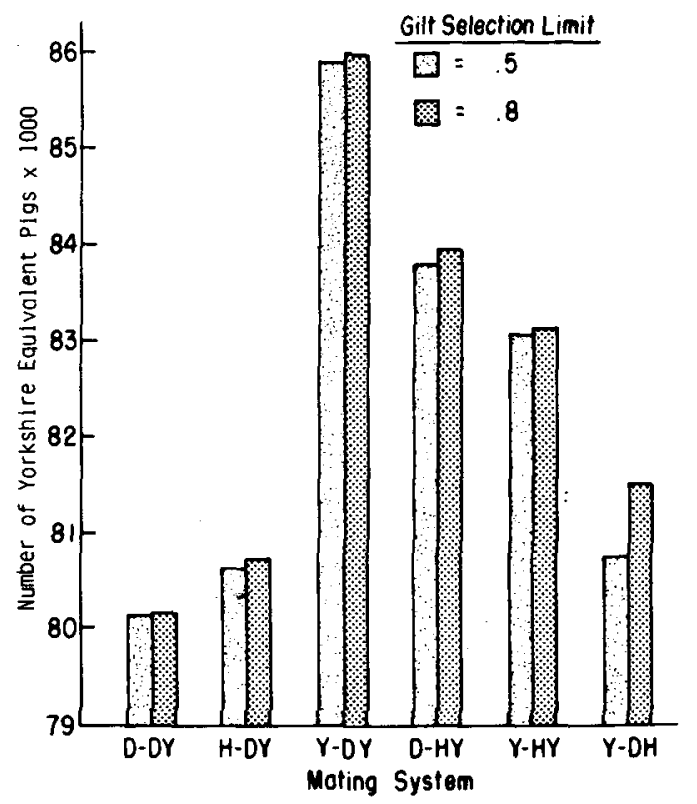

Figure 3. Comparison of number of Yorkshire equivalent pigs for six mating systems at two limits of purebred gilt selection.

half of the young boars could be retained for the breeding herd. This contributed to an excess of purebred gilts and increased effective selection intensity to less than $80 \%$. For the three-breed static systems $(H \times D Y$ and $D \times$ HY), production of Yorkshire equivalent pigs was decreased by $.2 \%$; however, the $\mathrm{Y} \times \mathrm{DY}$ system had a $1 \%$ loss of Yorkshire equivalent pigs. The differences in production due to changes in the proportion of gilts retained were similar when average retention rate of purebred sows was held constant and average retention rate for commercial sows was changed from 60 to $70 \%$.

An additional factor affecting productivity of mating systems is the length of time that a commercial sow is retained in production. Figure 4 shows the results of varying the average retention rate of commercial sows when the gilt selection limit is held constant at .8 and when $50 \%$ of the purebred sows producing $F_{1}$ gilts and farrowing two or more litters are retained. The total decrease in production as a result of changing the average retention from $70 \%$ to no commercial sows for more than two litters was $-2.82 \%,-3.22 \%,-3.39 \%,-2.80 \%$ and $-2.56 \%$ Yorkshire equivalent pigs for $\mathrm{Y} X$ $\mathrm{DY}, \mathrm{D} \times \mathrm{HY}, \mathrm{Y} \times \mathrm{DH}, \mathrm{DHY}$ rotation and $\mathrm{H}$ $X$ DY, mating systems, respectively.
Figure 5 compares the number of Yorkshire equivalent pigs produced by the $\mathrm{D} \times \mathrm{HY}, \mathrm{Y} \times$ $D Y$ and $Y X D H$ systems at various commercial sow retention rates when the purebred retention rate and proportion of purebred gilts selected is varied. In the $\mathrm{Y} \times \mathrm{DY}$ and $\mathrm{D} \times \mathrm{HY}$ system, a decrease from 70 to $60 \%$ in the average retention rate for commercial sows decreased total production by almost the same amount as a decrease from $50 \%$ to zero in the average retention rate for purebred sows producing crossbred offspring and farrowing two or more litters. In the $\mathrm{Y} \times \mathrm{DH}$ system, changes in the retention rates for purebred sows and(or) increases in the selection intensity for purebred gilts had a marked effect on production (figure 5). There did not appear to be important interactions among these three mating systems and different sow retention rates or gilt selection intensities.

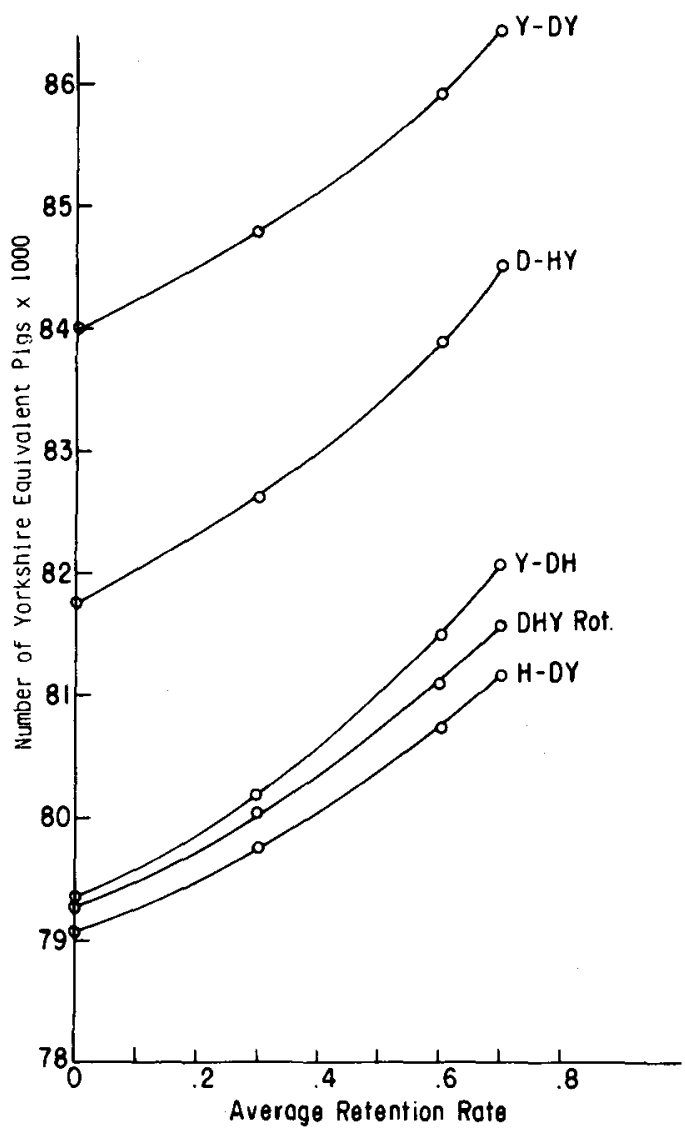

Figure 4. Number of Yorkshire equivalent pigs produced from five mating systems at various commercial sow retention rates. 


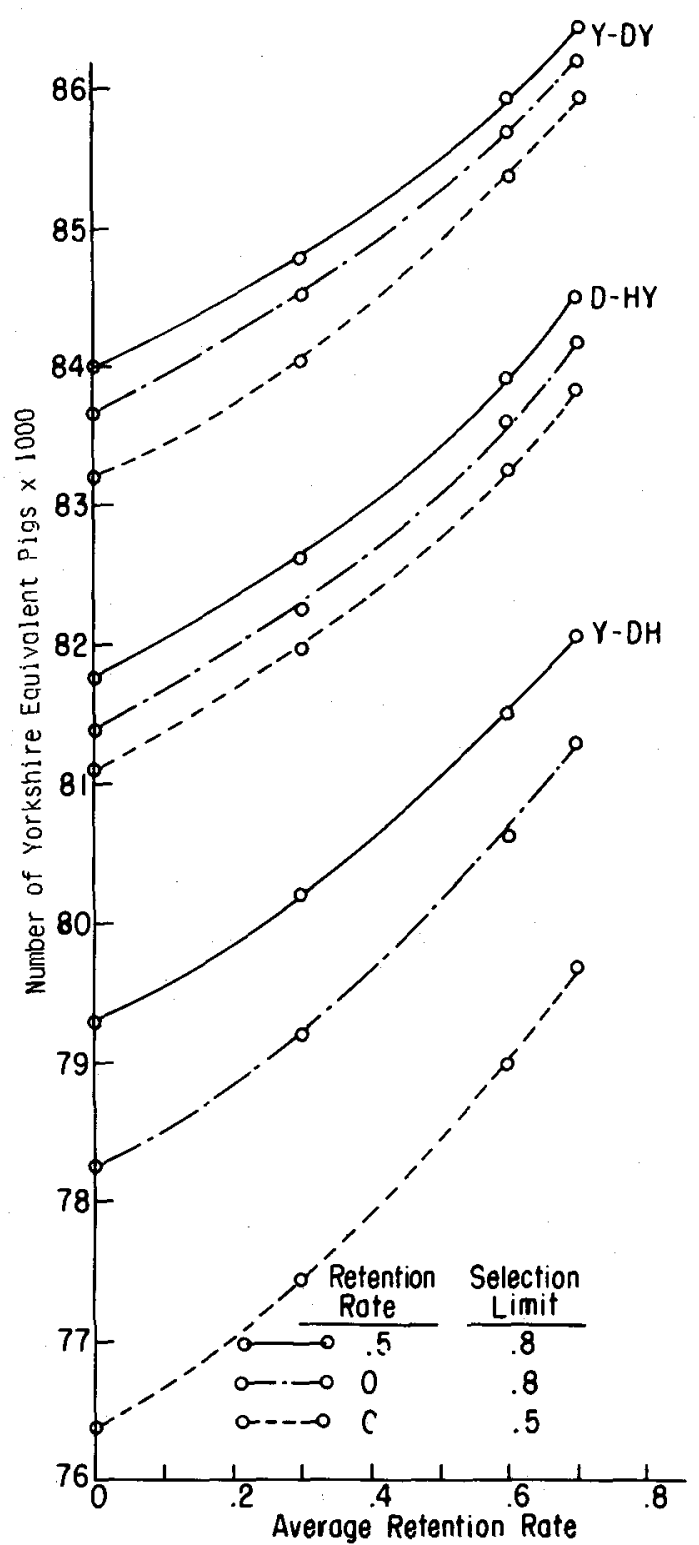

Figure 5. Comparison of mating systems at two gilt selection limits, two purebred sow retention rates and varied commercial sow retention rates.

Some factors to be considered in the choice of a mating system include: production of replacement females, use of maternal and paternal lines, selection practices, selection based on a general index or both maternal and paternal indices and balancing of future returns against present returns. The backcross system of $Y \times D Y$ produced the greatest number of Yorkshire equivalent pigs per 10,000 sows. Even though this system needs only two purebred herds and maintains maximum maternal heterosis, it does not allow for selection based on maternal and paternal lines. Smith (1964) has shown that selection in maternal and paternal lines will always be as effective as, and may be much more efficient than, selection in two lines based on a general index. A threebreed rotation system has the advantages of a high percentage of sows in commercial production and ease of gilt replacement production, but production is decreased by $3.3 \%$ when compared with that of the best three-breed static. The three-breed static cross $\mathrm{D} \times \mathrm{HY}$ has the second highest production rate and takes full advantage of the maternal and paternal traits of the three breeds. The $D \times H Y$ system also has the greatest number of Yorkshire equivalent pigs for the market pig producer, and selection can be based on maternal and paternal indexes. This selection scheme would need to be more effective over the long term than a general selection index in the $Y X D Y$ mating system for the $D X H Y$ system to become as efficient as $\mathrm{Y} \times \mathrm{DY}$. The three-breed static cross mating system is more complicated than a backcross or rotation system but may offer a good balance between present returns and selection opportunities for future improvement.

\section{Literature Cited}

Bereskin, B. and R. J. Davey. 1978. Genetic, sex and diet effects on pig carcass traits. J. Anim. Sci. $46: 1581$.

Bereskin, B., R. J. Davey and W. H. Peters. 1976. Genetic, sex and diet effects on pig growth and feed use. J. Anim. Sci. 43:977.

Bereskin, B., H. O. Hetzer, W. H. Peters and H. W. Norton. 1974. Genetic and maternal effects on pre-weaning traits in crosses of high- and low-fat lines of swine. J. Anim. Sci. 39:1.

Bereskin, B., C. E. Shelby and L. N. Hazel. 1971. Carcass traits of purebred Durocs and Yorkshires and their crosses. J. Anim. Sci. 32:413.

Cartwright, T, C., H. A. Fitzhugh, Jr. and C. R. Long. 1975. Systems analysis of sources of genetic and environmental variation in efficiency of beef production: Mating plans. J. Anim. Sci. 40:433.

Dickerson, G. E. 1969. Experimental approaches in utilizing breed resources. Anim. Breed. Abstr. 37:191.

Dickerson, Gordon E. 1973. Inbreeding and heterosis in animals. In Proceedings of the Animal Breeding and Genetics Symposium in Honor of Dr. Jay $L$. Lush, ASAS, ADSA, Champaign, IL.

Harris, Dewey L. 1970. Breeding for efficiency in livestock production: Defining the economic objectives. J. Anim. Sci. 30:860.

Johnson, R. K., I. T. Omtvedt and L. E. Walters. 1978. 
Comparison of productivity and performance for two-breed and three-breed crosses in swine. $J$. Anim. Sci. 46:69.

Moav, Rom. 19662 Specialized sire and dam lines I. Economic evaluation of crossbreds. Anim. Prod. 8: 193 .

Moav, Rom. 1966b. Specialized sire and dam lines III. Choice of the most profitable parental combination when component traits are genetically non-additive. Anim. Prod. 8:365.

Nelson, R. E. and O. W. Robison. 1976. Comparisons of specific two and three-way crosses of swine. J. Anim. Sci. 42:1150.

Nitter, G. 1978. Breed utilization for meat production in sheep. Anim. Breed. Abstr. 46:131.

Schneider, James F. 1976. Heterosis, combining ability and maternal ability estimated from single-crosses among four breeds of swine. M. S. Thesis. Iowa State Univ., Ames.

Smith, Charles. 1964. The use of specialized sire and dam lines in selection for meat production. Anim. Prod 6:337.

Young, L. D., R. K. Johnson and I. T. Omtvedt. 1976a. Reproductive performance of swine bred to produce purebred and two-breed cross litters. J. Anim. Sci. 42:1133.

Young, L. D., R. K. Johnson, I. T. Omtvedt and L. E. Walters. $1976 \mathrm{~b}$. Postweaning performance and carcass merit of purebred and two-breed cross pigs. J. Anim. Sci. 42:1124.

Wilson, E. R. and R. K. Johnson. 1981. Comparison of three-breed and backcross swine for litter productivity and postweaning performance. J. Anim. Sci. 52:18. 